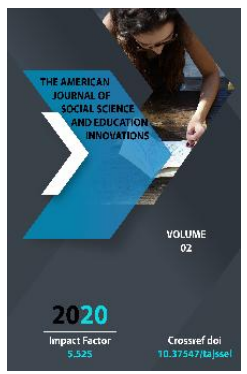

\title{
Lexical Occasionalisms And Its Relation To Related
} Phenomena

\author{
O.Yu. Tukhtasinova \\ Candidate of Philological Sciences, Associate Professor, Kokand State Pedagogical Institute, \\ Uzbekistan
}

Journal Website:

http://usajournalshub.c

om/index,php/tajssei

Copyright: Original content from this work may be used under the terms of the creative commons attributes 4.0 licence.

\section{ABSTRACT}

This article presents an analysis of the difference based on four criteria for the lexical interpretation of occasionalisms, the relationship between neologisms and occasionalisms, the relationship between a new word (neologism) and occasionalism.

\section{KEYWORDS}

Occasionalism, occasional word, occasional meaning, neologism, usual, usus, potential word.

\section{INTRODUCTION}

The study of the interrelationship of language and speech phenomena is one of the current issues in linguistics. The word, which is an important element of language, is the unity of language outside of speech, and the unity of speech in speech. This shows, on the one hand, the interdependence of language and speech, and, on the other hand, their close interdependence. Studies have shown that language and speech units are sharply differentiated phenomena $[1,2,3,4,5,6]$.

Unlike language units, speech units emerge as a product of the speech process. After all, the process of speech is a situation, a communicative space for the use of language units, the manifestation of their inherent semantic aspects. Therefore, the process of speech creates certain conditions for the 
realization of the meanings of different words. In speech, along with all linguistic units, words and phrases specific to an individual style of a creator are also used. They can remain as a speech phenomenon in the form of words specific to the text or an individual style of a creator, or they can quickly become active in speech activity, become part of the language and become its normative unit. Such words are called in linguistics by the term neologism, occasionalism. In linguistics, different views have been expressed on neologism and occasionalism. While some point to neologism and occasionalism as one concept, others point out that they are different.

Let's look at dictionaries first. O.S Akhmanova describes neologism as follows:

1. A word or phrase created to express a new object or new concept.

2. It is a new word or phrase that does not have the right to "citizenship" in general and is therefore considered to be specific, often, specific to the passive style of speech. Style neologism is a word that is considered a novelty when it occurs in a genre of a literary work. A word used in everyday life but not used in works of art. Stylistic neologism is a neologism created only by the author of a work of art and usually not widely used. Compare: gapaks eyremenon, potential word" [7].

"Hapax eimemenon (hapax legomenon, occasional word). "A word or phrase used" once "by a speaker or writer for a particular situation" [7].

A potential word, 1) that does not exist clearly (that is, has not yet been used in speech, even if it exists), but a simple or compound word which can be created at any moment in accordance with the productive word-forming pattern of a language; 2) words that are an element of phraseology and have the property of separation as a unit independent of it" [7].

\section{THE MAIN FINDINGS AND RESULTS}

The purpose of detailing these definitions in the dictionary is to give a clear expression of the concepts of occasionalism and neologism. We understand that O.S Akhmanova considers occasionalism as a neologism. Now let's look at other dictionaries.

Created in a particular piece of speech, living in that text, another uses the term occasional word or occasionalism (from the Latin word occasionalis - random) [8].

D.E. Rosenthal and M.A. Telenkova explain the neologism as follows: "Neologism (Greek neos - new + logos - word, concept). A word or phrase created to express a new subject or new concept (turn of speech). When the word becomes widely used, it does not become a neologism. Some neologisms of the Soviet era have become obsolete.

Stylistic (individual - stylistic) neologism. A neologism created by the author of a literary work for a specific stylistic purpose, but not widely available, not included in the lexicon of the language [9]. The same dictionary also focuses on occasionalism and occasional concepts: "Occasionalism. A word created on the basis of an inefficient word-formation pattern, used only in certain textual contexts. Compare: stylistic neologism".

"Occasional (Latin occasionalis - random). Incompatible with generally accepted applications, individual in nature, not dependent on a specific context (compare: uzual)"[9]. 
Let us also look at the definition given to the term uzual.

"Uzual. A word, phraseological phrase, grammatical construction, etc. that meets the usage requirement of a particular language community. (compare: occasional)".

"Uzus (Latin usus - tradition, rule, application). Words, fixed compounds, forms, constructions, etc., adopted for use by representatives of a particular language." [9].

Comparing the definitions given, it is clear that the lexicographers tried to avoid viewing occasionalism as a neologism. The descriptions given to the stylistic neologisms they point out are essentially similar to the descriptions of occasionalism, but the first contains the idea that "language is not part of the dictionary," which is not included in the second word description. The idea arises that occasionalisms are units that differ from neologisms, but the authors cannot say that they are strictly neologisms.

In A.Khojiev's “Explanatory Dictionary of Linguistic Terms" "Occasionalism is a neologism of individual style, a word based on a non-productive pattern, used only in the text itself. For example, like ice cream." The dictionary also gives an idea of occasional meaning: "Occasional meaning (lat. Occasionalis - random). The meaning that is not formed in the semantic structure of the word, but is realized in a particular individual application: Science, the whole of the flowers of art, gathered for a conversation (Oybek). Compare: uzual meaning" [10].

This commentary provides clear information about the Uzbek occasional word and occasional meaning. It seems that "occasionalism" can be used synonymously with the term "individual style neologism", because dictionaries provide regulated, standardized concepts. As long as attention is paid to occasionalisms in dictionaries, we think that this should be taken into account when enumerating their features.

A study of the existing scientific literature has shown that the feature of the emergence of occasionalism seems to be related in a certain sense to the concept represented by the neologism. But these linguistic phenomena are different. Below we express our opinion on this issue.

The relationship and difference between the new word (neologism) and occasionalism can be analyzed on the basis of the following four criteria:

1. Whether there is an author (creator). This criterion is not important for defining a new word. The new word is the fact of language. Occasional words are the fact of speech. One of the important features of an occasional word is that it belongs to an author. Most of these words are not recalled in memory. They are created for the first time by a person. Of course, it is not possible to know to whom the occasional words encountered in oral speech belong, which is hampered by the inconsistency, variability of oral speech, but written speech makes it much easier to find the creator of occasional words. In a word, occasional words belong in principle to a specific person - the creator of that occasional word. In language, however, every fact of it, including new words, is important only socially, that is, as an absolutely ownerless unit belonging to the community of all people who speak that language. Like all words in a language, when new owner is forgotten, new words are generalized and forgotten that they belong to specific authors. 
2. The novelty dimension of a word is important, but not absolute and mandatory for all new words. This dimension is mandatory only for modern new words, actual (active) new words, where the novelty of the word is felt. For example, merchant, collective farm, ministry, etc. began to be used in the 90s, now their novelty paint has disappeared.

The genetic core and principled basis of the concept of neologism is the novelty quality of the word. "So neologism is a very relative concept. It is a typical law that a neologism loses its color of novelty and becomes a regular, normal word. When the word now appears, it retains the character of a neologism while retaining the color of novelty. Until the new word is completely mastered by the language; will remain a neologism until it is added to the fund of the active reserve of the lexicon, that is, until it loses the shade of the supernatural" [11]. But even so, this feature is not unique to all new words. There is no such quality in (relatively) new words from past tenses, but it is present in actual new words. It is important to remember that relatively new words were relevant new words at the time. Because relevant new words inevitably become relatively new words over time. Feeling the novelty in the actual new words is a mandatory sign that this new word should be present. In general, the uniqueness of the new feature of the novelty feature is absolutely unquestionable. This feature is the basis of the general concept of neologism. In this sense, the following statements of $\mathrm{E}$. Begmatov on the essence of neologism are true: "Neologism is a new or the newest word according to the period of its emergence, in which the nuance of novelty is clearly felt. Neologism is a newly emerging word in language. It is a lexeme whose language has not yet passed into the ranks of normative words. As a result, neologisms are words that belong to the passive layer of the vocabulary[11]. The whole difficulty is that when analyzing this feature it cannot be quantified or formalized. This makes it very difficult for linguists to objectify and describe the feature being studied. For example, it is very difficult, if not impossible, to say how long a word that appears in a language will retain its novelty (and at the same time its neologism status). The more semantically relevant a word that appears in a language is, the stronger the verbal need for it, the more rapidly it joins the language process, the faster its novelty fades, and the shorter its duration as a neologism. For example, a number of new words today, such as minister, province, district, governor, teleconference, retiree, presentation, have lost their novelty due to the same extreme relevance and frequent use. Thus, new words are directly included in the general chain of historical changes in language, and are therefore subject to the same changes. Such a case, which is one of the principal conditions and signs of the concept of neologism, is alien to the occasional words as a separate speech fact, linguistically introduced because of the criterion of historical time.

3. Finally, it should be noted that new and random words are also very different depending on whether they are included in the language dictionary or not. There is no doubt that the new words are part of the language vocabulary (more precisely, they are part of the language). This is evidenced by the history of the literary language. Random words are the product of pure speech. A word that occurs only if it is a linguistic fact and is separated from the status of accidental (or does not have such a status at all) can be called a new word. 
E. Begmatov expresses the following views on new words in the Uzbek language and their linguistic features: "Along with the obsolescence of the language lexicon, it is also characterized by renewal. Just as it is natural for some words to become obsolete and obsolete, so it is natural for a new word to be born and created.... New lexical units that appeared in the Uzbek language in a new period form a new layer of words in the lexicon of this language. The new word is characterized by expressiveness - the color of novelty. The new word seems unnatural to the first encounter, especially to the older generation, familiar with the lexical norm of the old language. This is called lexical idiosyncrasy in linguistics." [11].

4. It is known that the historical time factor in the emergence of the word is one of the main features in the definition of the concept of neologism. Only words that can become obsolete over time and in the process of life, that can reduce the quality of their novelty, can be a new word. The emergence of a new word in a language took place during its historical formation. Therefore, in determining the neologism, the relative variability of the neologism is taken into account, depending on which historical period the word refers to.

As E. Begmatov correctly noted: "The novelty or obsolescence of a word depends on the period of its appearance in the language. The usability or obsolescence of a word depends on the functional activity or passivity of the lexemes" [11]. In this sense, every word can be called a neologism in principle in relation to the time of its occurrence. It is only necessary to determine when this or that word appeared in the language. For example, words such as kolxoz, sovxoz, traktor, traktorchi, pioneer are neologisms in the history of the Uzbek literary language of the 30 s of the XX century. Over time, they lost the color of novelty, became ingrained in the minds of language owners, began to be widely used, and took up a layer of active words. But today these words kolxoz, sovxoz, pioneer, have become obsolete and become historical words.

In the 1930s, a new group of words emerged based on different types of word formation. These are relatively variable, and their functions are studied in relation to a specific historical period, a clear text. That is why we have to talk about the neologisms of the $40 \mathrm{~s}$, 50s, 60s, 70s, 80s, 90 s of the XX century. The neologism of each period lives through various historical evolutions, gradually losing its novelty quality. "The creation of new words in a language is a product of the historical development of the language, its progress over time. Therefore, all newly formed words in a language can be studied not only synchronously, but also diachronically, that is, in terms of the fact that they appeared at a certain stage of language development" [12]. It follows that the new word concept is diachronic.

Occasional words have not only a nonmemorable property, but also a one-time and synchronous-diachronic confusion in terms of application [13]. Hence, they are irrelevant to historical time. Therefore, such words cannot be called neologisms.

Thus, a criterion of time is necessary in defining a new word, but as shown above, it is not absolute, it is viewed in terms of relativity.

Based on the above evidence, the new word can be defined as follows: A new word is a word that has the color of novelty, passing through the first stage of its historical life in the language. 
Thus, the term new word cannot be applied to occasional words because of their special properties. A new word is a completely diachronic concept that connects this or that argument (in this case the proof of the expression of a new word) to a particular fact. Occasional words are in principle "nonhistorical" because they are devoid of their "internal" history, because once used, most of them are not recovered in memory, and because of their synchronous-diachronic confusion, they are devoid of long-term survival in language. The emergence of occasional words is in any case connected with historical facts which are an external sign to it. For example, an occasional word may have a specific historical date of its occurrence, its own specific historical identity, its own author, as well as the reasons and circumstances that led to its occurrence. Such words, unlike stable (uzual) words, have a real history. It is devoid of features that change from time to time, i.e., it lacks internal development in the areas of lexical significance, stylistic color, expressiveness, word-forming structure, and so on.

\section{CONCLUSION}

The historical life of the occasional word has a point character, because its use does not, in principle, extend diachronically. Occasional words are not related to the temporal aspect of language, i.e., it cannot be called a new word or a stable word, regardless of the time of its appearance. A new word may be stamped on written texts, but when it is born in oral speech, it loses its life once the speech process is over. Occasional words belonging to the writers of different periods of the history of the Uzbek literary language (M.Shaykhzoda, H.Olimjon, U.Nosir, Cholpon, Mirtemir, etc.) have survived to the present day in the created text and have not changed, including obsolescence and activation; this was not possible due to its remoteness from the historical period factor. Hence, in this case, occasional words are far from a factor of historical development and change.

These features of occasional words, which we have shown, that is, their "obsolescence" in principle, have given rise to the more common notions of them as "constantly new words" or "forever new words".

In short, adding random words to a series of new words is impractical and incorrect. They represent an individual unit with a distinctive feature of speech.

\section{REFERENCES}

1. Steinthal G. Grammar, logic and psychology.

2. Zvegintsev V. Reader on the history of linguistics of the XIX-XX centuries. Part 1. Moscow: 1956. -p. 108.

3. Potebnya A. From notes on Russian grammar. Voronezh: 1874. -p. 43.

4. Vinogradov V.V. Russian language. Moscow: Uchpedgiz, 1947. -pp. 12-13.

5. Usmonov $\mathrm{S}$. Word as a unit of language and a unit of speech // Linguistic issues. Tashkent: Academy of Sciences of the USSR. 1963.

6. Ne'matov H; Bozorov O. Language and speech. Tashkent: Teacher. 1992

7. Akhmanova O.S. Dictionary of linguistic terms. Moscow: Sov. Encyclopedia. 1969.

8. Dictionary of foreign words. Moscow: Russian language. 1979. -p. 35.

9. Rosenthal D.E; Telenkova M.A. Dictionary - a reference book of linguistic terms. Moscow: Education. 1976. -p. 197. 
10. Xojiev A. Explanatory dictionary of linguistic terms. Tashkent: Teacher. 1985. -p. 63.

11. Lexicology of the Uzbek language. Tashkent: Science. 1981.

12. Timofeev K.A. On the basic concepts of word formation // Russian language at school. 1971. No. 3. - p.30.

13. Lykov A.G. Modern Russian lexicology (Russian occasional word). Moscow: Nauka. 1976. -pp. 12-14, 18-19. 